\title{
Comparative Analysis of Three Wind Turbines of Varying Blade Sizes
}

\author{
*Odia O. Osadolor ${ }^{1}$ and Ososomi A. Sunday ${ }^{2}$. \\ ${ }^{1}$ Faculty of Engineering and Technology, Ambrose Alli University, Ekpoma, Nigeria. \\ ${ }^{2}$ School of Engineering, Auchi Polytechnic, Auchi, Nigeria.
}

\begin{abstract}
This work focuses on the Comparative analysis of three Horizontal Axis Wind Turbines of varying blade sizes suitable for use in low wind regimes. The three turbines weredesigned to generate 250Watt, 140Watt and 62 Watt of power respectively at rated wind speed of $6.5 \mathrm{~m} / \mathrm{s}$. The three turbines were assembled and installed to run at a turbine height of $10 \mathrm{~m}$ each. The relevant measuring equipment were also installed and measurements were taking over a period of three months. The percentage performance of the turbines shows the follows; the $2 \mathrm{~m}$ blade turbine, $83.96 \%$; the $1.5 \mathrm{~m}$ blade turbine, $95.81 \%$; and the $1 \mathrm{~m}$ blade turbine, $94.89 \%$. However, on monthly average, the percentage performances are respectively, 57\%; $72.61 \% ; 87.24 \%$ for the $2 \mathrm{~m} ; 1.5 \mathrm{~m}$ and $1 \mathrm{~m}$ blade turbine. From the performance of the three turbines as explained above, it has been proved that whereas the size of the blade positively influence the amount of power produced, the efficiency of the wind turbine increases with decreasing size of the blades
\end{abstract}

Keywords: Wind, Turbine, Power, Blade, Comparative analysis

\section{Introduction}

The increasing demand of energy, the continuous reduction of available resources of fossil fuels and the growing concern regarding environmental pollution, demands that mankind needs to explore new technologies for power generation. The generation of electricity using clean renewable energy sources such as the wind energy, produces no $\mathrm{CO}_{2}$ emissions and therefore, will not contribute to the greenhouse effect. In the rural areas and other areas that are remote from the national grid where electricity is consequently a major challenge, wind energy will be very useful for providing electricity for household.

The evaluation of wind resource data at the site of interest is essential as the first step in assessing the potential for wind power and projecting turbine performance at that particular site of interest. The energy available in a wind stream is proportional to the cube of its speed, which means that doubling the wind speed increases the available energy by a factor of eight. Furthermore, the wind resource itself is seldom a steady, consistent flow. It varies with the time of day, season, height above ground, and type of terrain. At a turbine height of $10 \mathrm{~m}$, a cut-in wind speed of $2.5 \mathrm{~m} / \mathrm{s}$ is chosen for this design and at the rated wind speed of $6.5 \mathrm{~m} / \mathrm{s}$, all the three turbines are expected to perform to full capacity.

The fuel for this electricity generation is the wind and it is the most important constraint for the turbine design, as it creates loads the turbines have to withstand. To be able to effectively withstand these loads, all the various forces acting on the blade sections will be theoretically calculated and the designs will beoptimized to obtain the rated power output.

The aim of this work, therefore, is to compare the performance of three Horizontal Axis Wind Turbines that can work in relatively low wind regime. The three turbines are expected to operate simultaneously under the designed conditions and comparison will be made based on the power output measured on the site.

Taking $\mathrm{v}$ as the velocity of wind at the blades, $\rho$ is the density of the air and $\mathrm{A}$ is the area of the blade (Ragheb, M., 2011),

Maximum extractable power from wind,

$P_{\max }=\frac{16}{27} P_{\omega}=\frac{16}{27}\left(\frac{1}{2} \rho A V^{3}\right)$

Where $16 / 27=0.59259=59.26 \%$ is the Betz coefficient. The Betz Coefficient suggests that a wind turbine can extract about $59 \%$ of the energy in an undisturbed wind stream. Where the radius is equal to the blade length.

The actual power developed by a wind turbine is, however, a factor of the tip speed ratio. As the tip speed ratio of high speed wind turbine is 8 times that of the wind speed, the power coefficient, $\mathrm{C}_{\mathrm{p}}$ corresponding to this tip speed ratio will be 0.35 (Martin O.L., Hansen, 2008). 
Therefore, the practical power extractable from the wind is $\mathrm{P}_{\mathrm{p}}=0.35 \times \eta_{\mathrm{t}} \times \mathrm{P}_{\mathrm{ma}}$

Taking a transmission efficiency of $56 \%$

$\mathrm{P}_{\mathrm{p}}=0.35 \times 0.56 \times \mathrm{P}_{\max }=0.196 \mathrm{P}_{\max }$

Applying the above equations in congestion with other aerodynamics equationsthe data necessary for the design of the turbines can easily be determined.

\section{Methodology}

Using equations 1-3 and treating the blades as aerofoil sections all the parts of the wind turbines were designed and fabricated. The other parts of the turbine such as the generator, the tail vane, the tower, yaw drive mechanism, etc. were carefully selected and the three turbines were assembled and installed to run at a turbine height of $10 \mathrm{~m}$ each. The relevant measuring equipment were also installed, wattmeter, voltmeters and ammeters and measurement were taking over a period of three months.

\section{Result/Analysis}

Table 1: Results Obtained for the Month of December turbine 1: (2.0m Blade Length)

\begin{tabular}{|l|l|l|l|}
\hline Week & Average voltage (V) & Average Current (I) & Average Power (W) \\
\hline 1 & 8.77 & 10.59 & 95.59 \\
\hline 2 & 7.07 & 10.17 & 71.90 \\
\hline 3 & 11.36 & 16.95 & 192.55 \\
\hline 4 & 11.92 & 17.61 & 209.91 \\
\hline
\end{tabular}

Table 2: Results Obtained For the Month of December turbine 2: (1.5m Blade Length)

\begin{tabular}{|l|l|l|l|}
\hline Week & Average voltage (V) & Average Current (I) & Average Power (W) \\
\hline 1 & 8.17 & 10.40 & 84.97 \\
\hline 2 & 6.67 & 9.84 & 65.63 \\
\hline 3 & 9.13 & 13.34 & 121.79 \\
\hline 4 & 9.81 & 13.68 & 134.24 \\
\hline
\end{tabular}

Table 3: Results Obtained for the Month of December turbine 3: (1.0m Blade Length)

\begin{tabular}{|l|l|l|c|}
\hline Week & Average voltage (V) & Average Current (I) & Average Power (W) \\
\hline 1 & 5.90 & 9.00 & 53.10 \\
\hline 2 & 5.58 & 8.77 & 48.94 \\
\hline 3 & 6.19 & $\mathbf{8 . 9 6}$ & 55.46 \\
\hline 4 & 6.36 & 9.25 & 58.83 \\
\hline
\end{tabular}

Data collected at the site for the months of November and December are as depicted in tables 1, 2 and 3 and inFigs. 2 and 3. For the two months considered, it can be seen that the three turbines performed close to the rated capacity especially in the month of December. This implies that with more winds in the coming months the turbines are expected to perform even better.

It was also observed that the smallest turbine unit has a better starting performance than the other two. Furthermore, the percentage performance of the turbines at their bestas determined from tables 1, 2, and 3 are as follows: the $2 \mathrm{~m}$ blade turbine, $83.96 \%$; the $1.5 \mathrm{~m}$ blade turbine, $95.81 \%$; and the $1 \mathrm{~m}$ blade turbine, $94.89 \%$. However, on monthlyaverage, the percentage performances are respectively, $57 \% ; 72.61 \%$; $87.24 \%$ for the $2 \mathrm{~m}$; $1.5 \mathrm{~m}$ and $1 \mathrm{~m}$ blade turbine. Thus, the $1 \mathrm{~m}$ blade or smaller wind turbine operate well and better than the larger blade turbines at low wind speeds, though they have lower power output as also shown in Figs.2 and 3.Similarly, from Fig.2, it can be seen that the average power per week generated by the three turbines follows a given pattern. There is a rise in power from the first week up to the second week and thereafter the power begins to fall. The fall in power is as a result of the fall in the wind speed from the second to the fourth week in the month of November. In the month of December, however, there is a wide deviation from this pattern as shown in Fig.3. There is a rise in the power generated by all three turbines from the second week to the fourth week. The rise in power is due to the change in weather occasioned by the so-called harmattan season. 


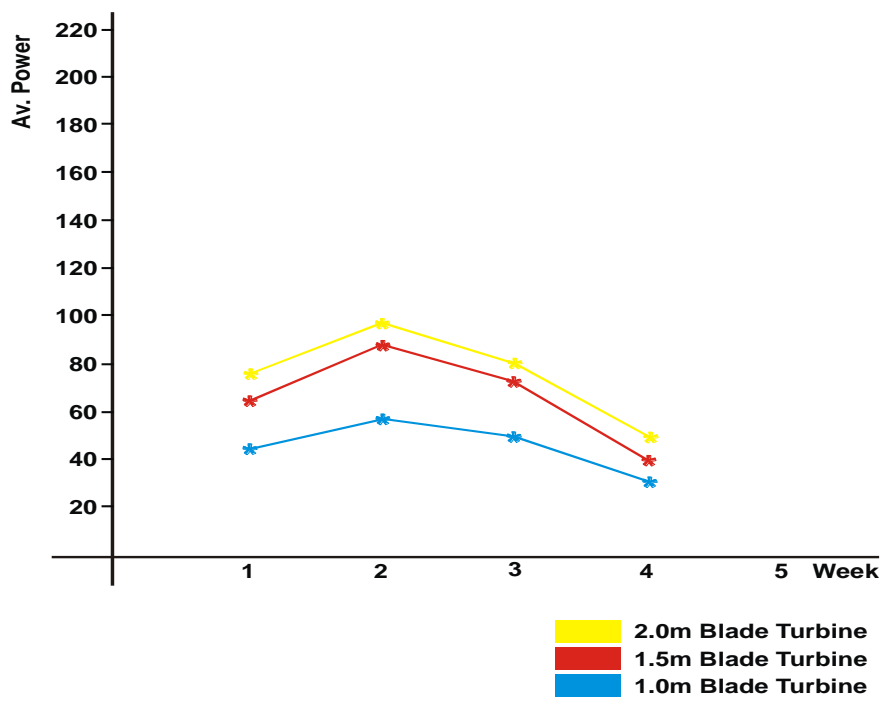

Fig.1. Average Power generated per Week in the month of November

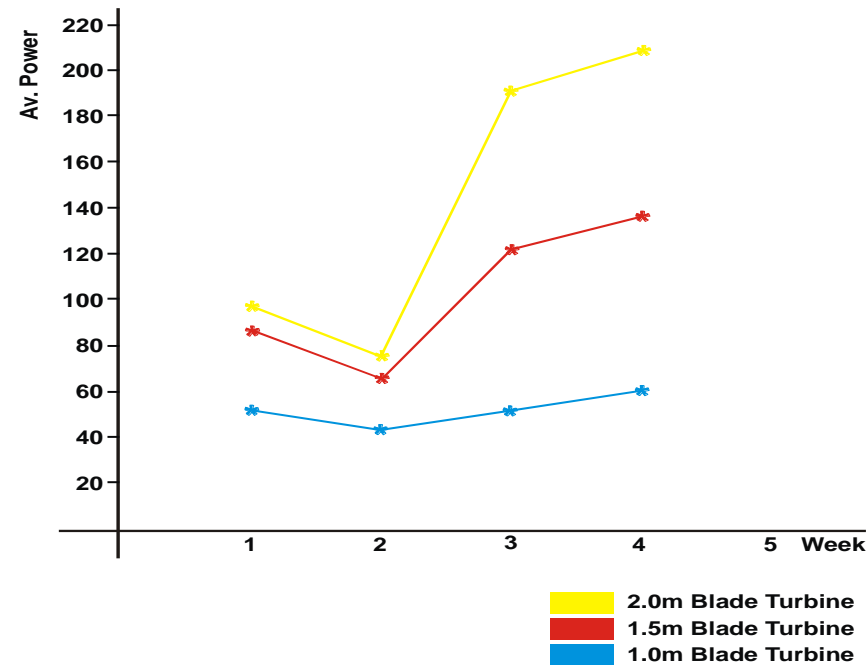

Fig.2. Average Power generated per Week in the month of December

\section{Conclusion}

The suitability of a wind turbine for low wind speed regime is its ability to extract power at that low wind speed. From the performance of the three turbines as explained above, it has been proved thatwhereas the size of the blade positively influence the amount of power produced, the efficiency of the wind turbine increases with decreasing size of the blades. This evidently is as a result of reduction in aerodynamic loses associated with reduced size of blades.

\section{References}

[1]. Calvert, N.G, 1979. "Windpower Principles: Their Application on the Small Scale", Charles Griffin \& Co. Ltd, London, England.

[2]. Dane Witt up, 2013. Wind Power for the World: The Rise of Modern Wind Energy.www.academia.edu/.../9814364932

[3]. De Vries, O. 1979. Fluid Dynamic Aspects of Wind Energy Conversion, Agardograaph.No.243, Advisory A rough Aeronautical Research and Development. https://books.google.com.ng/books

[4]. Enrich Hau, 2006. Wind Turbines. Fundamentals, Technologies, Applications and Economics, Third, Translated Edition, Springer Heidelberg, New York.

[5]. Martin O. L. Hansen, 2008. Aerodynamics of Wind Turbines, $2^{\text {nd }}$ Edition, Earth scan Publications, UK.

[6]. Mort horst, Paul Erik, 2002. A Green Certificatation Market for Developing Renewable Energy Technologies: Conference ArticleAnnual Report. ENERBulletin,No25, P.41-47

[7]. Mort horst, P.E; 2003. Wind Power and the Conditions at a Liberalized Power Market. Journal Article- Annual Report, Vol.6, P.297-308.

[8]. Prandtl, L. and Tietjens, O.G, 1957. Applied Hydro and Aerodynamics, Dover Publications, New York.

[9]. Ragheb, M, 2011. "Wind Power Systems. Harvesting the Wind" .http://netfiles.uiuc.edu/mragheb/www

[10]. Thomas Ackerman, Ed; 2005. "wind power in Power Systems", John Wiley and Sons, Ltd.UK

[11]. Triton, D.J, 1988. Physical Fluid Dynamics, $2^{\text {nd }}$ Edition, Oxford University Press 